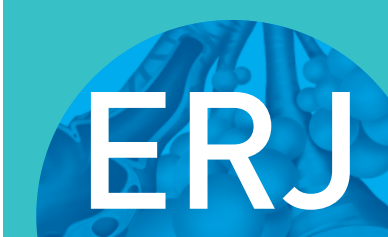

open research
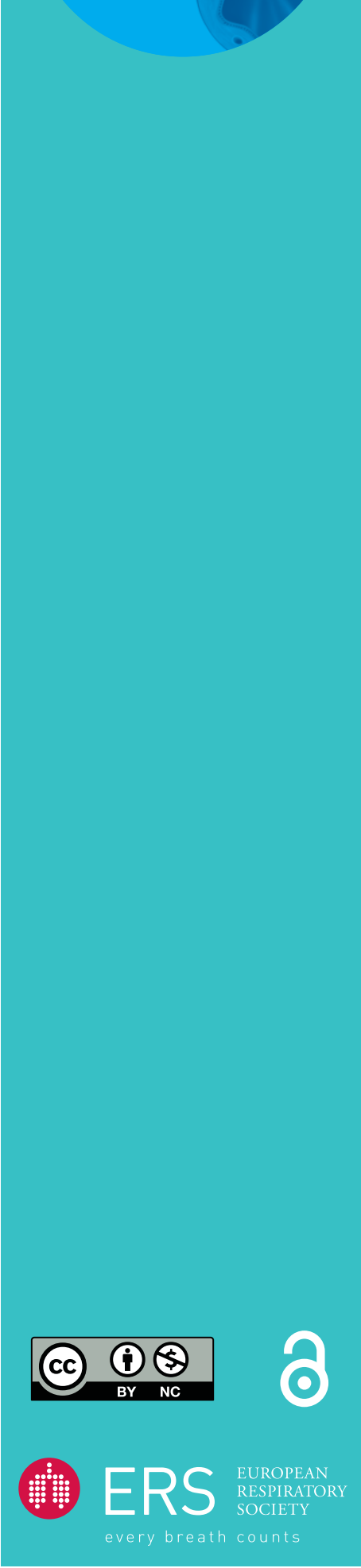

\section{The influence of active and passive air humidification on exhaled breath condensate volume}

\author{
Jeppe Hjembaek-Brandt (10),2, Mathias Hindborg ${ }^{1,2}$, Andreas K. Jensen ${ }^{3,4}$, \\ Christian Ari Dalby Sørensen ${ }^{1,2}$, Bodil Steen Rasmussen ${ }^{5,6}$, \\ Raluca Georgiana Maltesen ${ }^{5}$ and Morten Heiberg Bestle ${ }^{1,2}$
}

\begin{abstract}
Affiliations: 'Dept of Anaesthesia and Intensive Care, Nordsjællands Hospital, Hillerød, Denmark. ${ }^{2}$ Dept of Clinical Medicine, University of Copenhagen, Copenhagen, Denmark. ${ }^{3}$ Dept of Public Health, Section of Biostatistics, University of Copenhagen, Copenhagen, Denmark. ${ }^{4}$ Dept of Clinical Research, Nordsjaellands Hospital, Hillerød, Denmark. ${ }^{5}$ Dept of Anaesthesia and Intensive Care, Aalborg University Hospital, Aalborg, Denmark. ${ }^{6}$ Clinical Institute, Aalborg Universitet, Aalborg, Denmark.
\end{abstract}

Correspondence: Jeppe Hjembaek-Brandt, Dept of Anaesthesia and Intensive Care, Nordsjaellands Hospital, Dyrehavevej 29, Hillerød 3400, Denmark. E-mail: jeppe.brandt.02aregionh.dk

ABSTRACT Exhaled breath condensate (EBC) is safely collected in mechanically ventilated (MV) patients, but there are no guidelines regarding humidification of inhaled air during EBC collection. We investigated the influence of active and passive air humidification on EBC volumes obtained from MV patients.

We collected 29 EBC samples from 21 critically ill MV patients with one condition of active humidification and four different conditions of non-humidification; 19 samples from 19 surgical MV patients with passive humidification and two samples from artificial lungs MV with active humidification. The main outcome was the obtained EBC volume per $100 \mathrm{~L}$ exhaled air.

When collected with different conditions of non-humidification, mean [95\% CI] EBC volumes did not differ significantly $(1.35[1.23 ; 1.46]$ versus $1.16[1.05 ; 1.28]$ versus $1.27[1.13 ; 1.41]$ versus $1.17[1.00 ; 1.33]$ $\mathrm{mL} / 100 \mathrm{~L}, \mathrm{p}=0.114)$. EBC volumes were higher with active humidification than with non-humidification (2.05 [1.91; 2.19] versus $1.25[1.17 ; 1.32] \mathrm{mL} / 100 \mathrm{~L}, \mathrm{p}<0.001)$. The volume difference between these corresponded to the EBC volume obtained from artificial lungs $(0.81[0.62 ; 0.99]$ versus $0.89 \mathrm{~mL} / 100 \mathrm{~L}$, $\mathrm{p}=0.287$ ). EBC volumes were lower for surgical MV patients with passive humidification compared to critically ill MV patients with non-humidification (0.55 [0.47;0.63] versus $1.25[1.17 ; 1.32] \mathrm{mL} / 100 \mathrm{~L}$, $\mathrm{p}<0.001)$.

While active humidification increases EBC volumes, passive humidification decreases EBC volumes and possibly influences EBC composition by other mechanisms. We propose that EBC should be collected from MV patients without air humidification to improve reproducibility and comparability across studies, and that humidification conditions should always be reported.

@ERSpublications

When collected from mechanically ventilated (MV) patients, the volume of exhaled breath condensate (EBC) is influenced by both active and passive air humidification. EBC should be obtained from MV patients without air humidification if possible. https://bit.ly/2WC5G7B

Cite this article as: Hjembaek-Brandt J, Hindborg M, Jensen AK, et al. The influence of active and passive air humidification on exhaled breath condensate volume. ERJ Open Res 2020; 6: 00009-2020 [https://doi.org/10.1183/23120541.00009-2020].

Received: 7 Jan 2020 | Accepted after revision: 17 June 2020

Copyright $\odot$ ERS 2020. This article is open access and distributed under the terms of the Creative Commons Attribution Non-Commercial Licence 4.0. 


\section{Introduction}

Exhaled breath condensate $(\mathrm{EBC})$ is a biological fluid formed by directing exhaled air through a refrigerated device, whereby the exhaled air condenses [1]. The main components of EBC are water ( $>99.9 \%)$ and volatile and non-volatile compounds derived from the lining fluid of the respiratory tract $[1,2]$. These compounds in EBC have been shown to reflect pathology of the airways [3]; for example, KosTIKAS et al. [4] was able to discriminate between healthy controls and patients with chronic obstructive pulmonary disease, bronchiectasis and asthma by means of $\mathrm{EBC} \mathrm{pH}$, and CArraro et al. [5] found that nuclear magnetic resonance (NMR) spectroscopy of EBC outperforms the widely used measurements of $\mathrm{FEV}_{1}$ (forced expiratory volume in $1 \mathrm{~s}$ ) and exhaled nitric oxide as markers of asthma in children.

EBC is a valuable matrix for investigating pulmonary disease because it can be collected in a quick, non-invasive and repeatable fashion [6]. These characteristics are significant advantages to methods such as bronchoscopy, bronchoalveolar lavage and tissue biopsy that are invasive, time-consuming and associated with considerable discomfort and risks (including compromised ventilation and iatrogenic lung injury or infection) and therefore cannot be performed repeatedly $[3,5]$.

EBC is easily and safely collected from mechanically ventilated (MV) patients [3]. However, the existing guidelines do not specify whether inhaled air should be humidified or not during specimen collection in these patients $[3,6]$. This is an important issue in the context of EBC research because both MV critically ill and surgical patients are routinely MV with either actively or passively humidified air [7]. While active humidifiers are external sources of heat and moisture, passive humidifiers (also known as heat and moisture exchangers (HMEs)) retain heat and moisture from the patient's exhaled breaths and return it to the subsequently inhaled breaths [7]. Active humidifiers are placed in the inspiratory limb of the ventilatory circuit, and passive humidifiers are placed between the Y-piece and the patient [7].

The lack of humidification guidelines has resulted in inconsistent methodologies in studies of EBC from MV patients. While some investigators have collected EBC with ongoing air humidification [8-12], others have removed the humidifier from the ventilatory circuit prior to sample collection [13-20], and yet others have not reported their humidification conditions [21-29]. Importantly, MüLLER et al. [30] found that EBC concentrations of 8-isoprostane in MV children increased significantly when patients were ventilated with non-humidified instead of actively humidified air during EBC collection, suggesting that active air humidification dilutes the obtained EBC samples. In addition, we found that EBC collected with active air humidification was too diluted for metabolite quantification on an NMR spectroscope (unpublished data). As such, we identified only 1-2 compounds in each actively humidified EBC sample, which is significantly less than reported in other NMR studies of EBC. For example, MотTA et al. [31] identified more than 20 compounds in EBC from spontaneously breathing subjects.

This dilution of EBC is problematic because analysis of EBC is already complicated by methodological uncertainties partially caused by the varying sample dilution that inherently characterises the EBC matrix [2]. It is therefore of interest to investigate the effect of active and passive air humidification on the volume of obtained EBC to identify the optimal method for EBC collection in the MV patient.

Lastly, condensate inherently forms in the ventilator tubing of MV patients [7]. We hypothesised that this condensate might re-evaporate after the active humidifier is turned off and subsequently condense in the EBC sample, resulting in increased EBC volumes. We therefore investigated whether this effect, if present, is relevant to $\mathrm{EBC}$ collection by measuring the obtained $\mathrm{EBC}$ volume after increasingly minimising the amount of humidity and/or condensate in the ventilatory circuit.

\section{Materials and methods}

\section{Study subjects}

The study was approved by the Regional Committee on Health Research Ethics (journal number: H-16038167) and the Danish Data Protection Agency (journal number: NOH-2017-019, L-suite number: 05889).

Two patient groups were included: critically ill MV patients in the intensive care unit (ICU) (group P) and MV surgical patients (group S).

Patients were included in group $\mathrm{P}$ if they were urgently admitted to the ICU, $\geqslant 18$ years of age and endotracheally intubated within the last $24 \mathrm{~h}$. Written informed consent was obtained from patient proxies after patient inclusion. In accordance with the Declaration of Helsinki, written informed consent was obtained from patients themselves when they were able. If patients were irreversibly incapacitated or died before consent could be obtained, consent from patient proxies was considered sufficient. Group P patients were MV with Evita Infinity V500 ventilators (Dräger, Lübeck, Germany). When relevant (see below), air humidification was achieved by means of active humidifiers (Evaqua $2^{\mathrm{TM}}$ RT380, Fisher \& Paykel 
Healthcare Ltd, Auckland, New Zealand), which fully saturate the inhaled air with water vapour and heat the inhaled air to $37^{\circ} \mathrm{C}$.

Patients were included in group S if they were $\geqslant 18$ years of age, MV in relation to planned gynaecological surgery and gave written informed consent prior to their inclusion. Group S patients were MV with Primus anaesthesia workstations (Dräger, Lübeck, Germany). Air humidification in group S was achieved by means of passive humidifiers (Humid-Vent ${ }^{\oplus}$ Filter Compact, Teleflex, Athlone, Ireland).

No halogenated anaesthetics were given in either patient group. Patient care was not impacted and no adverse events in relation to EBC collection were observed.

The effect of active and passive air humidification on EBC volume

To investigate the effect of active humidification on the obtained EBC volume, EBC samples were collected from patients in group $\mathrm{P}$ under one condition of active air humidification and four different conditions of non-humidification as described in table 1 . The specific humidification condition(s) were chosen individually based on an assessment by the attending physician of the patient's predicted tolerance of the intervention(s).

To investigate the effect of passive humidification on the obtained $\mathrm{EBC}$ volume, EBC samples were collected from patients in group $\mathrm{S}$ who were MV with passive humidifiers.

EBC was also collected from artificial lungs connected to Evita Infinity V500 ventilators with ongoing active air humidification during sample collection. While the tidal volume was $500 \mathrm{~mL}$ in this group, all other respiratory settings were identical to those described in the section below. .

The primary outcome was the obtained EBC volume per $100 \mathrm{~L}$ exhaled air.

\section{EBC collection}

In group $\mathrm{P}, \mathrm{EBC}$ was collected as soon as possible after endotracheal intubation (EI) with one or more of the conditions of air humidification listed in table 1. In group S, EBC was collected immediately after EI and before the start of surgery.

EBC was collected with a commercially available device (TURBO-DECCS 14, Medivac, Parma, Italy). The device was pre-cooled to $-5.5^{\circ} \mathrm{C}$ before being inserted into the expiratory limb of the ventilatory circuit as described elsewhere [3], and operated at $-5.5^{\circ} \mathrm{C}$ throughout $\mathrm{EBC}$ collection. The ambient temperature at the time of sample collection was not measured. Sample collection time was $15 \mathrm{~min}$ in the actively humidified groups ("+H" and "V500") and $20 \mathrm{~min}$ in all other groups. If actual collection times differed from these times, the volume of obtained EBC was controlled for this difference because exhaled air volume influences the obtained EBC volume [6]. When clinically possible, patients in all groups were ventilated in volume control mode with tidal volume $8 \mathrm{~mL} \cdot \mathrm{kg}^{-1}$, respiratory frequency $12 \mathrm{~min}^{-1}, \mathrm{~F}_{\mathrm{i}} \mathrm{O}_{2}$ $100 \%$, positive end-expiratory pressure $10 \mathrm{cmH}_{2} \mathrm{O}$ and inspiratory:expiratory ratio 1:2. EBC volumes were

\section{TABLE 1 The groups and subgroups of the present study}

\section{Group description}

Critically ill MV patients; active humidification

Active humidification turned on prior to and during EBC collection Active humidification turned off...

... 10 min prior to and during EBC collection

... $\overline{\mathbf{6 0}}$ min prior to and during EBC collection

$\ldots .60 \mathrm{~min}$ prior to and during EBC collection, and replacement of ventilator

tubing prior to EBC collection

60 min prior to and during EBC collection, and replacement of ventilator

tubing and humidifier chamber prior to EBC collection

MV surgical patients; passive humidification

Artificial lungs ventilated with $\mathbf{V 5 0 0}$ ventilators; active humidification

\section{Group}

abbreviation

Group P

$+\mathrm{H}$

$-\mathrm{H}$ pooled

$-\mathrm{H} 10$

$-\mathrm{H} 60$

$-\mathrm{H} 60 \mathrm{~T}$

$-\mathrm{H} 60 \mathrm{TH}$

Group S, +Passive V500

The conditions of air humidification prior to and during EBC collection are described in the left-hand column, and the abbreviations for the groups in the right-hand column. The numbers and letters used in the abbreviations are underscored in their respective descriptions. Each EBC sample belongs in only one group, but some patients had EBC collected under more than one condition. EBC: exhaled breath condensate; MV: mechanically ventilated. 
measured immediately after collection. The volume of exhaled air during specimen collection was calculated as the product of minute volume and collection time.

\section{Statistical analysis}

Patient characteristics were expressed as median [interquartile range (IQR)]. Normally distributed data were compared with Student's t-test while non-normally distributed data were compared with the Mann-Whitney $U$-test. Categorical data were compared with the Pearson $\chi^{2}$ test.

Mean EBC volumes were modelled by a linear mixed effect regression model with group as a factor covariate with either six or three levels and a random intercept on patients. A likelihood ratio test with three degrees of freedom was used to assess whether the four non-humidified subgroups could be collapsed into a single group $(-\mathrm{H}$ pooled). The distribution of the test statistic was simulated under the null hypothesis using a parametric bootstrap with 25000 simulations. 95\% confidence intervals were similarly calculated by a parametric bootstrap of the profile likelihood and the percentile method. Pair-wise comparisons of groups were adjusted for multiplicity by the Tukey method. V500 was considered a fixed value in the analysis because its two measurements were numerically equal.

p-values below $5 \%$ were considered statistically significant.

\section{Results}

\section{Patient characteristics}

We collected a total of $29 \mathrm{EBC}$ samples from 21 patients in group P, 19 samples from 19 patients in group $\mathrm{S}$ and two samples in group V500. Baseline characteristics of the two patient groups are shown in table 2.

As seen in table 2, patients differed in most baseline characteristics, including ventilatory parameters. Only patients in group $\mathrm{P}$ were suspected to be infected, with the lungs being the most common infection site.

\section{The effect of different conditions of air humidification on EBC volume}

The EBC volumes obtained from the different study groups are presented in table 3 and figure 1.

A likelihood ratio test showed that the non-humidified subgroups of group "-H pooled" did not differ significantly in the mean volumes of EBC obtained $(\mathrm{p}=0.114)$. Based on this result, the remaining comparisons were done with group "-H pooled" instead of the individual subgroups, as shown in figure 1 .

A comparison of group " $+\mathrm{H}$ " versus " $-\mathrm{H}$ pooled" showed that these groups differed significantly in the mean volumes of EBC obtained $(\mathrm{p}<0.001)$. The difference in mean [95\% CI] volumes between these groups $(0.81[0.62 ; 0.99] \mathrm{mL} / 100 \mathrm{~L})$ did not differ significantly from the volume obtained in group "V500" $(0.89 \mathrm{~mL} / 100 \mathrm{~L})(\mathrm{p}=0.287)$.

\section{TABLE 2 Baseline characteristics of patients in group P and group S}

\begin{tabular}{|c|c|c|c|}
\hline & Group $P(n=21)$ & Group $S(n=19)$ & p-value \\
\hline Male [n (\%)] & $13(62 \%)$ & $0(0 \%)$ & $<0.001$ \\
\hline Age (y) & $63[55 ; 75]$ & $49[42 ; 55]$ & $<0.001$ \\
\hline Suspected infection [n (\%)] & $15(71 \%)$ & $0(0 \%)$ & $<0.001$ \\
\hline Pulmonary infection & $12(57 \%)$ & $0(0 \%)$ & $<0.001$ \\
\hline Abdominal infection & $1(5 \%)$ & $0(0 \%)$ & 0.347 \\
\hline Urinary infection & $4(19 \%)$ & $0(0 \%)$ & 0.050 \\
\hline Sepsis/septic shock & $5(24 \%)$ & $0(0 \%)$ & 0.027 \\
\hline Other infection & $4(19 \%)$ & $0(0 \%)$ & 0.050 \\
\hline Steroid treatment at EI [n (\%)] & $6(29 \%)$ & $18(95 \%)$ & $<0.001$ \\
\hline Antibiotic treatment at EI [n (\%)] & $11(52 \%)$ & $6(32 \%)$ & 0.139 \\
\hline \multicolumn{4}{|c|}{ Ventilatory parameters at EBC collection } \\
\hline Respiratory frequency $\left(\mathrm{min}^{-1}\right)$ & $13[12 ; 15]$ & $12[12 ; 12]$ & 0.001 \\
\hline Tidal volume $\left(\mathrm{mL} \cdot \mathrm{kg}^{-1}\right)$ & $8.0[7.4 ; 8.2]$ & $7.4[7.3 ; 7.7]$ & 0.023 \\
\hline $\mathrm{F}_{\mathrm{i}} \mathrm{O}_{2}(\%)$ & $100[85 ; 100]$ & $97[96 ; 97]$ & 0.008 \\
\hline PEEP $\left(\mathrm{cm} \mathrm{H}_{2} \mathrm{O}\right)$ & $10[10 ; 10]$ & $10[10 ; 10]$ & 0.046 \\
\hline Peak pressure $\left(\mathrm{cm} \mathrm{H}_{2} \mathrm{O}\right)$ & $23[22 ; 25]$ & $20[19 ; 21]$ & 0.002 \\
\hline Time from El to EBC collection (h) & $10.9[4.9 ; 18.3]$ & $0.0[0.0 ; 0.0]$ & $<0.001$ \\
\hline
\end{tabular}

Data are shown as median [IQR] or $\mathrm{n}(\%)$. EBC: exhaled breath condensate; El: endotracheal intubation; $\mathrm{F}_{\mathrm{O}} \mathrm{O}_{2}$ : fraction of oxygen in inspired air; IQR: interquartile range; PEEP: positive end-expiratory pressure. 


\section{TABLE 3 Mean [95\% CI] EBC volumes obtained from the different study groups}

Group

\section{Group P}

$+H(n=6)$

$-\mathrm{H}$ pooled $(\mathrm{n}=23)$

$-\mathrm{H} 10(\mathrm{n}=7)$

$-\mathrm{H} 60(\mathrm{n}=8)$

$-\mathrm{H} 60 \mathrm{~T}(\mathrm{n}=4)$

- H60TH (n=4)

Group $S,+$ Passive $(n=19)$

V500 $(n=2)$

EBC volume per $100 \mathrm{~L}$ exhaled air $(\mathrm{mL})$

$2.05[1.91 ; 2.19]$

$1.25[1.17 ; 1.32]$

$1.35[1.23 ; 1.46]$

$1.16[1.05 ; 1.28]$

$1.27[1.13 ; 1.41]$

$1.17[1.00 ; 1.33]$

$0.55[0.47 ; 0.63]$

0.89

Group abbreviations are elaborated in table 1. EBC: exhaled breath condensate.

A comparison of group "-H pooled" versus "+Passive" showed that these groups differed significantly in the mean volumes of EBC obtained $(\mathrm{p}<0.001)$. The difference in mean $(95 \% \mathrm{CI})$ volume between these groups was $0.70 \mathrm{~mL} / 100 \mathrm{~L}[0.57 ; 0.82]$.

Only one subject was diagnosed with acute respiratory distress syndrome (ARDS) at the time of sample collection; this subject was in group " $+\mathrm{H}$ ". The volume of this subject's EBC sample $(2.34 \mathrm{~mL} / 100 \mathrm{~L}) \mathrm{did}$ not differ significantly from the mean volume of the five other samples in group " $+\mathrm{H}$ " $(1.99 \pm 0.19 \mathrm{~mL} /$ $100 \mathrm{~L}, \mathrm{p}=0.07)$.

\section{Discussion}

We found that the condition of air humidification has a significant influence on the EBC volume obtained per $100 \mathrm{~L}$ exhaled air from MV patients. Specifically, the mean [95\% CI] EBC volume increased by more than $60 \%$ when inhaled air was actively humidified versus non-humidified during EBC collection (2.05 [1.91; 2.19] versus $1.25[1.17 ; 1.32] \mathrm{mL} / 100 \mathrm{~L}, \mathrm{p}<0.001)$. The difference between EBC volumes collected with actively humidified versus non-humidified air in group P did not differ significantly from the EBC volume obtained from artificial lungs ventilated with active humidifiers $(0.81$ [0.62;0.99] versus $0.89 \mathrm{~mL} /$ $100 \mathrm{~L}, \mathrm{p}=0.287$ ). We conclude that the difference in $\mathrm{EBC}$ volumes between humidified versus non-humidified conditions is caused by condensation of pure water supplied by the active air humidifier.

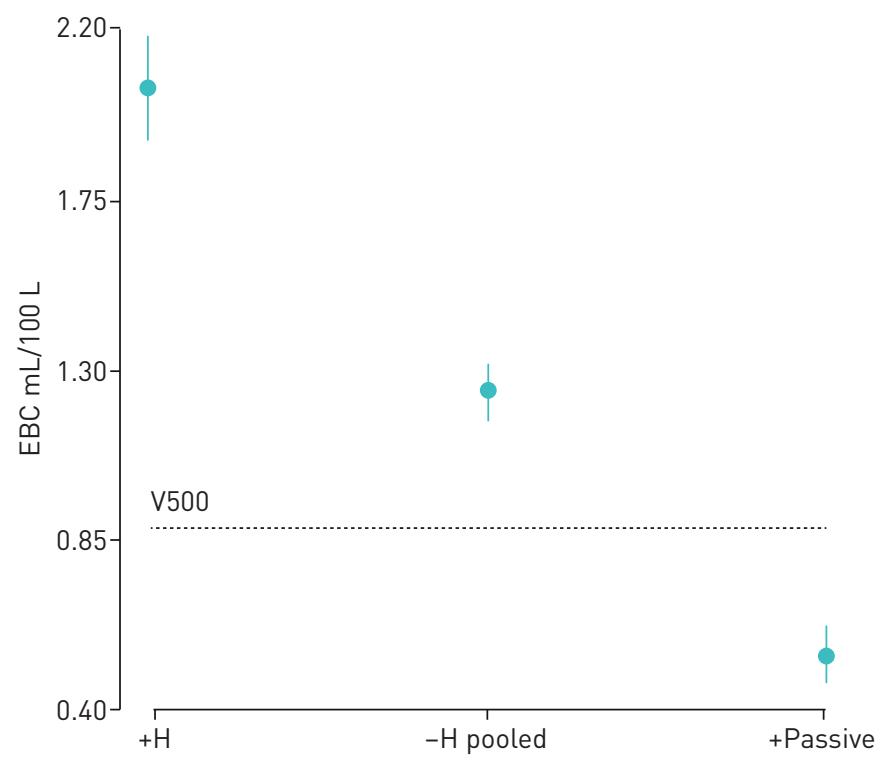

FIGURE 1 Mean $(95 \%$ CI) EBC volumes obtained from the different study groups when pooling the non-humidified subgroups of group P. The horizontal line depicts the EBC volume obtained from group V500. Group abbreviations are elaborated in table 1. EBC: exhaled breath condensate. 
We found no difference in EBC volumes as a function of ARDS status at sample collection. However, only one subject was diagnosed with ARDS at the time of sample collection. We therefore consider the sample size far too small to conclude anything meaningful about the influence of ARDS status on EBC volume.

Moisture in the patient's exhaled air (originating both from active humidifiers and the patient's own breaths) inherently condenses in the ventilator tubing on both the inspiratory and expiratory side of the ventilatory circuit in MV patients [7]. We hypothesised that, when active humidification is turned off, this condensate might re-evaporate into the inhaled air and subsequently condense in the EBC sample, resulting in increased $\mathrm{EBC}$ volumes. We therefore investigated the effect of increasing the time between deactivation of the active humidifier and EBC collection on the obtained EBC volume, as well as the effect of replacing the ventilator tubing and/or humidification chamber immediately prior to EBC collection. These increasing efforts to minimise humidity and/or condensate in the ventilatory circuit produced no significant difference on the obtained EBC volume as seen in table $3(\mathrm{p}=0.114)$.

We conclude that active air humidification increases EBC volumes per $100 \mathrm{~L}$ exhaled air, presumably diluting the EBC in line with the results reported by MÜLLER et al. [30]. We propose that active humidifiers are turned off 10 min prior to and during $\mathrm{EBC}$ collection because increasing the time between humidifier deactivation and $\mathrm{EBC}$ collection, as well as changing the tubing and/or humidifier, provides no additional benefit in terms of minimising EBC volume. This small intervention is presumably tolerated by most patients, will presumably increase non-volatile compound concentrations in the EBC and will ultimately improve the comparability and reproducibility across future studies of $\mathrm{EBC}$ from MV patients, albeit the effect size is relatively small. Additionally, our results indicate that EBC samples obtained with any condition of non-humidification can be readily compared.

Interestingly, MCCAFFERTY et al. [32] reported that spontaneously breathing patients produced a mean $\pm \mathrm{SD}$ of $627 \pm 258 \mu \mathrm{L} \mathrm{EBC}$ when breathing ambient air with a minute volume of $8.6 \mathrm{~L} \cdot \mathrm{min}^{-1}$ for $6 \mathrm{~min}$, which equals $1.22 \pm 0.5 \mathrm{~mL}$ EBC per $100 \mathrm{~L}$ exhaled air. This result corresponds well with the EBC volume obtained in group "-H pooled" $(1.25[1.17 ; 1.32] \mathrm{mL} / 100 \mathrm{~L})$, indicating that spontaneously breathing healthy subjects and critically ill MV patients produce similar volumes of EBC when breathing non-humidified air. In addition, VAUGHAN et al. [22] found that EBC $\mathrm{pH}$ was similar when collected from the same patients either orally or endotracheally but did not report the patients' humidification conditions during mechanical ventilation. It is therefore possible that EBC collected from MV patients ventilated with non-humidified air might be compared to EBC collected from spontaneously breathing patients, but this cannot be directly concluded from our data. We found that group S patients MV with passive humidification produced less than $50 \%$ of the EBC produced by patients in group " $-\mathrm{H}$ pooled" $(0.55$ [0.47; $0.63]$ versus $1.25[1.17 ; 1.32] \mathrm{mL} / 100 \mathrm{~L}, \mathrm{p}<0.001)$. Although it is a limitation to our study that group $\mathrm{S}$ patients differed from group $\mathrm{P}$ patients in terms of baseline gender and disease conditions as well as ventilatory parameters, we find it most likely that the observed difference in EBC volumes is caused by the HMEs found in the ventilatory circuits of group $S$ patients. The HME preserves moisture on the patient side of the HME and thereby decreases the amount of moisture on the ventilator side of the HME, which must ultimately decrease the volumes of obtained EBC. We cannot conclude from the present study whether the composition of the obtained EBC is altered by the HME. However, because HMEs trap aerosols in the exhaled breath (and thereby non-volatile compounds that might otherwise have sedimented in the obtained EBC) [7], it seems intuitive that EBC composition might be altered by HMEs. Based on our findings, we propose that actively humidified, passively humidified and non-humidified EBC should be thought of as different samples that cannot be directly compared. In this regard, Fermier et al. [21] performed an EBC metabolomics study in which they accurately discriminated critically ill MV patients and MV surgical patients. The investigators, however, reported conflicting values of EBC yield $(1 \mathrm{~mL}$ versus $2-3 \mathrm{~mL}$ per $20 \mathrm{~min}$ in their Methods and Results section, respectively, with no assignment to patient groups) and did not report the conditions of air humidification in their patient groups. Assuming that the patient groups were MV with active and passive humidification, respectively (which their conflicting values of obtained EBC volume might indicate), our results indicate that their discrimination of groups might be at least partially due to the confounding effect of having different humidification conditions in the groups. This is, however, only speculation because humidification conditions were not reported in the mentioned study. It does, however, serve to emphasise the importance of reporting the humidification conditions of MV patients in the context of EBC research.

Several other efforts than ours have been made to minimise dilution and variability of EBC. These have included lyophilisation and resuspension of the sample (which is, however, associated with a risk of insoluble aggregate formation) [1] and fractionation of exhaled air so that the obtained EBC is formed by condensation of exclusively alveolar air [9,33]. For spontaneously breathing patients, WiNTERs et al. [34] developed an active feedback method for EBC collection to minimise variability in breathing patterns. A recent study showed that EBC protein concentrations decline sharply with time, emphasising the need for 
prompt analysis of EBC samples [35]. As such, there are several different methods to increase the compound concentrations found in EBC. The relative importance of these precautions is not quite clear. However, reducing EBC volume by turning off the active humidifier does not seem to be of great importance because this measure only reduces the EBC volume by a factor of less than 2 . This is not a particularly significant dilution factor in the context of analytical chemistry and is certainly less than the factors achieved by deploying some of the methods mentioned above.

In addition, we did not routinely measure the temperature of the inhaled or exhaled air. As a result, we cannot comment on the influence of air temperature on EBC volume, even though this would have been interesting to know, given that relative air humidity depends on the temperature of the air [7].

In conclusion, humidification of inhaled air during EBC collection in MV patients has a significant but relatively small influence on the obtained volumes of EBC per $100 \mathrm{~L}$ exhaled air. Active humidification increases EBC volumes, presumably diluting the non-volatile compounds in the samples. Passive humidification decreases EBC volumes but might influence EBC compound content by other mechanisms. The different conditions of non-humidification investigated in the present study do not differ from each other and result in volumes of EBC that can be readily compared to those obtained from spontaneously breathing, healthy controls.

We propose that future studies of EBC from MV patients are conducted with no kind of air humidification during sample collection when the patient's condition allows it. Our results show that turning off the active humidifier $10 \mathrm{~min}$ before and during EBC collection reduces the volume of water in the EBC sample derived from the humidifier. This small intervention is presumably tolerated by most patients, will presumably increase non-volatile compound concentrations in the EBC and will ultimately improve the comparability and reproducibility across future studies of $\mathrm{EBC}$ from MV patients, albeit the effect size is relatively small. It is important that investigators always report the humidification conditions when collecting EBC from MV patients.

Acknowledgements: We thank research nurses Sanne Lauritzen and Lone Valbjørn (Dept of Anaesthesiology and Intensive Care, Nordsjaellands Hospital, Hillerød, Denmark) for assistance with sample collection, and obtaining informed consent from patient proxies and patients.

Support statement: The authors are grateful for funds received from a research grant from Nordsjællands Hospital (16515-e-20221, 17549-e-20834, 19552-e-20834). Funding information for this article has been deposited with the Crossref Funder Registry.

Conflict of interest: None declared.

\section{References}

1 Horvath I, Hunt J, Barnes PJ, et al. Exhaled breath condensate: methodological recommendations and unresolved questions. Eur Respir J 2005; 26: 523-548.

2 Effros RM, Hoagland KW, Bosbous M, et al. Dilution of respiratory solutes in exhaled condensates. Am J Respir Crit Care Med 2002; 165: 663-669.

3 Carter SR, Davis CS, Kovacs EJ. Exhaled breath condensate collection in the mechanically ventilated patient. Respir Med 2012; 106: 601-613.

4 Kostikas K, Papatheodorou G, Ganas K, et al. $\mathrm{pH}$ in expired breath condensate of patients with inflammatory airway diseases. Am J Respir Crit Care Med 2002; 165: 1364-1370.

5 Carraro S, Rezzi S, Reniero F, et al. Metabolomics applied to exhaled breath condensate in childhood asthma. Am J Respir Crit Care Med 2007; 175: 986-990.

6 Horvath I, Barnes PJ, Loukides S, et al. A European Respiratory Society technical standard: exhaled biomarkers in lung disease. Eur Respir J 2017; 49: 1600965.

7 Al Ashry HS, Modrykamien AM. Humidification during mechanical ventilation in the adult patient. Biomed Res Int 2014; 2014: 715434.

8 Walsh BK, Mackey DJ, Pajewski T, et al. Exhaled-breath condensate $\mathrm{pH}$ can be safely and continuously monitored in mechanically ventilated patients. Respir Care 2006; 51: 1125-1131.

9 Vaschetto R, Corradi M, Goldoni M, et al. Sampling and analyzing alveolar exhaled breath condensate in mechanically ventilated patients: a feasibility study. J Breath Res 2015; 9: 047106.

10 Gessner C, Hammerschmidt S, Kuhn H, et al. Exhaled breath condensate acidification in acute lung injury. Respir Med 2003; 97: 1188-1194

11 Gessner C, Dihazi H, Brettschneider S, et al. Presence of cytokeratins in exhaled breath condensate of mechanical ventilated patients. Respir Med 2008; 102: 299-306.

12 Cheah FC, Darlow BA, Winterbourn CC. Problems associated with collecting breath condensate for the measurement of exhaled hydrogen peroxide from neonates on respiratory support. Biol Neonate 2003; 84: 338-341.

13 Korovesi I, Papadomichelakis E, Orfanos SE, et al. Exhaled breath condensate in mechanically ventilated brain-injured patients with no lung injury or sepsis. Anesthesiology 2011; 114: 1118-1129.

14 Roca O, Gomez-Olles S, Cruz MJ, et al. Mechanical ventilation induces changes in exhaled breath condensate of patients without lung injury. Respir Med 2010; 104: 822-828. 
15 Carpenter CT, Price PV, Christman BW. Exhaled breath condensate isoprostanes are elevated in patients with acute lung injury or ARDS. Chest 1998; 114: 1653-1659.

16 Kietzmann D, Kahl R, Muller M, et al. Hydrogen peroxide in expired breath condensate of patients with acute respiratory failure and with ARDS. Intensive Care Med 1993; 19: 78-81.

17 Roca O, Gomez-Olles S, Cruz MJ, et al. Effects of salbutamol on exhaled breath condensate biomarkers in acute lung injury: prospective analysis. Crit Care 2008; 12: R72.

18 Fernandez-Bustamante A, Klawitter J, Repine JE, et al. Early effect of tidal volume on lung injury biomarkers in surgical patients with healthy lungs. Anesthesiology 2014; 121: 469-481.

19 Shyamsundar M, McAuley DF, Shields MO, et al. Effect of simvastatin on physiological and biological outcomes in patients undergoing esophagectomy: a randomized placebo-controlled trial. Ann Surg 2014; 259: 26-31.

20 Arcencio L, Vento DA, Bassetto S, et al. Exhaled nitrite/nitrate levels as a marker of respiratory complications after heart valve surgery. J Crit Care 2013; 28: 533.e1-7.

21 Fermier B, Blasco H, Godat E, et al. Specific metabolome profile of exhaled breath condensate in patients with shock and respiratory failure: a pilot study. Metabolites 2016; 6: 26

22 Vaughan J, Ngamtrakulpanit L, Pajewski TN, et al. Exhaled breath condensate $\mathrm{pH}$ is a robust and reproducible assay of airway acidity. Eur Respir J 2003; 22: 889-894.

23 Hitka P, Cerny M, Vizek M, et al. Assessment of exhaled gases in ventilated preterm infants. Physiol Res 2004; 53 561-564

24 Kononikhin AS, Starodubtseva NL, Chagovets VV, et al. Exhaled breath condensate analysis from intubated newborns by nano-HPLC coupled to high resolution MS. J Chromatogr B Analyt Technol Biomed Life Sci 2017; 1047: 97-105.

25 Fernandez R, Gili G, Villagra A, et al. Assessment of the inflammatory effect of low-dose oxygen in mechanically ventilated patients. Intensive Care Med 2013; 39: 711-716.

26 Sznajder JI, Fraiman A, Hall JB, et al. Increased hydrogen peroxide in the expired breath of patients with acute hypoxemic respiratory failure. Chest 1989; 96: 606-612.

27 Yen E, Weinberger BI, Laumbach RJ, et al. Exhaled breath condensate nitrite in premature infants with bronchopulmonary dysplasia. J Neonatal Perinatal Med 2018; 11: 399-407.

28 Yu Y, Zhu C, Liu C, et al. Diagnostic performance of soluble triggering receptor expressed on myeloid cells-1 in ventilator-associated pneumonia of patients with ischemic stroke. Can J Infect Dis Med Microbiol 2017; 2017 9513690

29 Garcia-de-la-Asuncion J, Garcia-del-Olmo E, Perez-Griera J, et al. Oxidative lung injury correlates with one-lung ventilation time during pulmonary lobectomy: a study of exhaled breath condensate and blood. Eur J Cardiothorac Surg 2015; 48: e37-e44.

30 Muller WG, Morini F, Eaton S, et al. Safety and feasibility of exhaled breath condensate collection in ventilated infants and children. Eur Respir J 2006; 28: 479-485.

31 Motta A, Paris D, D'Amato M, et al. NMR metabolomic analysis of exhaled breath condensate of asthmatic patients at two different temperatures. J Proteome Res 2014; 13: 6107-6120.

32 McCafferty JB, Bradshaw TA, Tate S, et al. Effects of breathing pattern and inspired air conditions on breath condensate volume, $\mathrm{pH}$, nitrite, and protein concentrations. Thorax 2004; 59: 694-698.

33 Trischler J, Merkel N, Konitzer S, et al. Fractionated breath condensate sampling: $\mathrm{H}(2) \mathrm{O}(2)$ concentrations of the alveolar fraction may be related to asthma control in children. Respir Res 2012; 13: 14

34 Winters BR, Pleil JD, Angrish MM, et al. Standardization of the collection of exhaled breath condensate and exhaled breath aerosol using a feedback regulated sampling device. J Breath Res 2017; 11: 047107.

35 Nunez-Naveira L, Marinas-Pardo LA, Montero-Martinez C. Mass spectrometry analysis of the exhaled breath condensate and proposal of dermcidin and S100A9 as possible markers for lung cancer prognosis. Lung 2019; 197: 523-531. 